\section{Exploring caring leadership through a feminist ethic of care: The case of a sporty CEO}

\author{
Janet Johansson
}

Department of Management and Engineering, Linköping University, Linköping, Sweden

\section{Michaela Edwards}

HR and OB, Nottingham Business School, Nottingham, UK
Leadership

202I, Vol. 0(0) I-18

(C) The Author(s) 2021

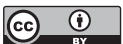

Article reuse guidelines: sagepub.com/journals-permissions DOI: 10.1 I77/I7427I5020987092 journals.sagepub.com/home/lea

(SAGE

\begin{abstract}
This work critiques the normative construction of ethical leadership and contributes to understanding the ethics of care in leadership from a lifestyle and embodied perspective. Drawing on feminist notions of ethics of care, we question the ethicality of the practices of a sporty and health-oriented leader who claims to transform his attempts at self-care into care for others through role-modelling lifestyle behaviours. We explore inherent moral dilemmas in connecting a seemingly creative self-care project with well-intentioned practices of caring for others. We highlight the need to question persistent masculine rationalisations in ethical leadership, and to engage in and encourage, organisational and relational interactions that take account of specific employee needs. We argue that the leaders' claiming to care for others by insisting on particular lifestyle behaviours and role-modelling aesthetic bodily ideals introduce new managerial norms in the organisation. The Instrumental intentions come to hamper an ethical care for the well-being of employees, whilst demonstrating the power of the leader to influence employees both inside and outside the organisation.
\end{abstract}

\title{
Keywords
}

Ethical leadership, health and lifestyle, feminist ethics of care, ethics of self-care, ethics of care for others

\section{Introduction}

The notion of self-concept has been essential in the normative construction of ethical leadership (Bass and Avolio, 1993). In recent years, leadership studies have explored how some leaders attempt

\section{Corresponding author:}

Janet Johansson, Department of Management and Engineering (IEI), Linköping University, Linköping 58I83, Sweden.

Email: janet.johansson@liu.se 
to build a moral foundation by presenting themselves as healthy/athletic leaders. Many athletic CEOs in Sweden use lifestyle behaviours in sporting activities to create new attributes of leadership identity (Johansson, 2017; Johansson et al., 2017). They impact upon employees' wellness behaviours in and outside the workplace (Johansson et al., 2017; Maravelias, 2015; Thanem, 2013) through offering up particular modes of being that they often construct as authentic and true to their own beliefs (Johansson, 2017). The discourse around health/wellness has a positive moral valence, while disease or illness has a negative valence (Conrad, 1994). Thus, leaders who strive to become role models to their employees through enacting particular lifestyles create a new health ethics in their organisations (Conrad and Walsh, 1992) and regard themselves as ethical (Johansson, 2017). Nonetheless, Price (2018) expressed scepticism' towards the normative construction of ethical leadership by pointing out the lack of theoretical scrutiny of ethics and argued that the ethicality in leadership is often reduced to gestures of 'normative appropriateness' (Brown et al., 2005: 120) regarding how to behave.

The notion of care has played an essential part in leadership research. Ciulla emphasises that leadership is a practice that 'includes caring for others, or taking responsibility for them' (Ciulla, 2009: 3). Among the athletic leaders, new behavioural norms that begin with 'self-care' are being demonstrated as guides to new moral conduct for others (Johansson, 2017). The intention here is often to care for the employee through presenting an ethical and healthy self-image for others to follow (e.g. Brown et al., 2005; Brown and Treviño, 2006; Johansson, 2017). More broadly, a pervasive health and well-being discourse has grown in much of Western society, promoting 'healthy' lifestyles and associating this with ethical business practices. As a typical example, in the United Kingdom alone, between 74 and 99 billion pounds was lost due to poor mental health (Stevenson and Farmer, 2017); and healthy workplaces, physical and mental, are reviewed and promoted by the Chartered Institute for Personnel Development (CIPD, 2019). Critical literature has, however, considered the power relations inherent in such discourses and revealed possible dysfunctional outcomes (Harvey, 2019) through problematising the reinforcing of ableism (Foster, 2017) and the marginalisation of disabled bodies, maternal bodies (Gatrell, 2015) and unwellness (Cederstrom and Spicer, 2015; Dale and Burrell, 2014; Spicer and Scott, 2015) in workplaces.

We, along with other critical scholars, recognise that it is ethically problematic that leadership practices that are meant to 'care' by taking account of employees' satisfaction and well-being, are at risk of being eroded by managerial notions and reduced to the imposition of appropriated behaviours (e.g. Britton 2000; Britton and Logan 2008; Islam, 2013; Johansson, 2017; Price, 2018; Rhodes and Pullen, 2018). Taking feminist ethics of care as the theoretical lens, we, therefore, question whether the self-regarded ethical leadership practices involving the promotion of aspirational lifestyles can support an ethic of care for others (e.g. Brown and Treviño, 2006). Drawing from a Swedish CEO's attempts to care for his employees through the promotion of 'healthy' lifestyles within his organisation, we aim to contribute to critical leadership literature concerning the normative construction of ethical leadership within a broader range of critical scholarship interrogating the promotion of corporate wellness in Western contexts.

\section{Literature review and the theoretical frame}

\section{The normative construction of ethical leadership}

Previous work emphasises the relational dimension of the ethical practice of leaders while making a connection between leaders' sense of self and attentiveness to others (Brown et al., 2005). Brown et al. (2005) note that ethical leaders affect the self-concept and beliefs of followers through role modelling and amplifying moral values and identities for their followers. Avolio, Bass, Gardner and 
others highlight the self in their discussion of care in leadership (Avolio et al., 2004; Bass and Avolio, 1993; Gardner and Avolio, 1998; Brien, 1998: 391; Knights and O'Leary, 2006). They draw on Heidegger's (1996) definition of care as an attention to one's own presence, for example the 'true self' in the world. This not only highlights the perceived importance of a leader's self-concept, moral values and identities as a basis for ethical practices, but also designates leaders with caregiving responsibilities within their organisations.

The wider leadership literature becomes relevant to the relationship between a leader's selfconcept and ethical leadership. Caring and serving others has been said to be a core element of the broader 'servant' and 'transformational/authentic' leadership literature. Here, caring relationships and bonds between the leader and followers are seen as key (Kouzes and Posner, 2014). Within authentic leadership, in particular, leaders are often regarded as ethical if they are clearly aware of how they think and behave and are perceived by others as being attentive to their own and others' moral perspectives, knowledge and strength (Avolio et al., 2004a; Avolio and Gardner, 2005). Hence, ethical leaders' care and concern for others are often regarded as paramount to ethicality within the broader leadership literature (Brown and Treviño, 2005: 599).

Furthermore, ethical leadership often encourages leaders to achieve morality by maintaining a stable emotional, cognitive state so that they may be perceived as 'authentic' and ethical to followers. Thus, the perfectionist self is often central (Avolio and Gardner, 2005; Bass and Steidlmeier, 1999; Brown et al., 2005). However, Brown et al. (2005) critique the connection between the perfectionist self of leaders and the ethical leadership of followers. They argue that 'authenticity and self-awareness are not part of the ethical leadership construct because "authenticity or being true to oneself was not recognised by followers as part of leaders' 'ethical conduct"” (Brown et al., 2005: 599).

Moreover, research into leadership and care emphasises the importance of care-based perspectives and relational approaches to the moral foundations of ethical and effective leadership as care has been seen to nurture cognitive trust at work (Dirks and Ferrin, 2002). However, it has been pointed out that any linkage between the 'moral self' and ethical care for others may depend upon whether the focus is on scrutinising allegedly moral elements of ethical leadership or subordinates' perceptions (Ciulla, 2004; Price, 2018).

Price (2018) critiqued normative descriptions concerning how leaders 'should' behave or care to act ethically. This 'normatively appropriate content' is problematic because it can become about how practices or behaviours are perceived in cultures rather than attention to an ethical framework (Price, 2018). Subordinates are often bound up in the partiality of power relationship in leadership contexts. Therefore, we cannot solely take the subordinates' perceptions to be definitive indicators of what constitutes ethical leadership (Brown and Treviño, 2006; Price, 2018). Based on this, Price (2018) argued for the importance of critically scrutinising ethical leadership by engaging with moral theories. We aim to add to the critique of 'normatively appropriate content' by employing feminist theories of care ethics to question the ethicality of placing the leader's self-concept at the centre of ethical practices of care.

\section{Wellness programmes and leaders' self-concept}

The well-being agenda or the 'Wellness Syndrome' (Cederstrom and Spicer, 2015) has come to dominate much of the interface between work and wellness in Western contexts. The definition of wellness is contested but has been defined in terms of changing one's lifestyle and adopting healthpromoting behaviours (e.g. Knowles 1977; Coriel, Levin and Jaco, 1986, in Conrad, 1994: 387). Morality and health are often linked (Conrad, 1994). However, here we follow those who question the moralising of the body and the well-being agenda at work more broadly (Cederstrom and Spicer, 
2015; Dale and Burrell, 2014; Islam, 2013) and those who question the operationalising of a perfectionist self to influence others (Crocket, 2017; Johansson, 2017; Thanem 2013 etc.).

Indeed, a project of the self (Foucault, 1986; 1994; Markula, 2003; Markula and Pringle, 2006) can be conducted through health/sport. Regulated diet and exercise are regarded as efforts that people engage in to enhance physical and emotional mastery, to modify body shape or to improve performance. These efforts can be docile responses in relation to dominant discourses of societal bodily ideals and normative strivings for power, success and competitiveness (Ptrie and Greenleaf, 2011). Yet, simultaneously, alternative athletic selves may be produced seeking renewed selfcreation through sport (Crocket, 2017). Building upon Foucault, Markula (2003) contends that the ethicality of self-care arises from a concern for one's actions as an ethical subject aiming at the renewal of the self (p. 99). This explains how, among many leaders, lifestyle behaviours have become moral indicators of self-discipline, self-control and reflexive self-creation (e.g. Johansson, 2017; Maravelias, 2015).

However, the self-presentational practices around sporty identities affect how leaders and employees interact, and how different categories of employees, the sporty and the seemingly less than sporty, may be viewed by each other and management. Johansson et al. (2017) find that managers who engage in vigorous sporting activities outside the workplace invoke their lifestyle behaviours to forge a form of gendered managerial regulation in organisations. Thanem (2013) revealed that managers who promote wellness activities at work are perceived as transgressing leadership boundaries by employees. These studies have shed light on the understanding that lifestyle behaviours that derive from intentions to care for the self can change the quality of the relation between leader and employees. We build on this by thinking through how this type of organisational regulation and a focus on the perfectionist self relate to an understanding of ethical leadership embedded in a feminist ethic of care. We problematise attempts to leverage self-care to promote particular behaviours to others.

Undeniably, wellness behaviours contain positive moral indications. As Crocket (2017) stated, practices such as moderation, tolerance and honesty offer a range of methods to facilitate the production of an athletic self to show care for self and others (p. 31). Nevertheless, the promotion of good health at work is also found to be implemented purposefully to facilitate instrumental, managerial intentions (Conrad and Walsh, 1992; Johansson, 2017) and can obscure the 'unwellness' that organisational forms often demand (Dale and Burrell, 2014). Islam (2013) finds that employees are often used to maximise productivity, detracting attention 'from issues of human care and dignity' (p. 236). He calls for future research to take a feminist ethic of care into account (Islam, 2013). Recent work by Rhodes and Pullen also suggests that, 'business ethics needs to go beyond the conclusion that ethics is simply a means through which corporations pursue economic self-interest' (2018: 495). In response to these calls, we follow our critical colleagues and apply a feminist ethic of care to problematise the link between leaders' caring of the self and caring for others via the promotion of healthy lifestyle behaviours. We question whether the actions of leaders in an attempt to care for others through modelling care of the self can be constructed as practices of an ethics of care. We concern ourselves with the unintended consequences of focussing on the promotion of the (male) athletic body, with the potential alienation of other types of body, and intrusions upon private life.

\section{Feminist theories of an ethics of care}

Feminist theorists on an ethics of care advocate that caring for others begins with a perspective of 'persons as relational and interdependent, morally and epistemologically', rather than viewing 
individuals as independent, self-sufficient actors (Held, 2006: 13). For example Noddings (2003) highlighted the importance of the emotional aspect of care, suggesting that 'to care is to act not by fixed rule but by affection and regard' (p. 24). Therefore, to care for others is not to impose solutions for problem-solving purposes, 'to care means to respect the other's autonomy and to work to enhance the cared-for's ability to make their own choices well' (Liedtka, 1996: 184). Hence, an ethic of care does not promote dependence on others due to power structures, but it emphasizes freedom of choice and action.

Held explained (2006) that the "central focus of the ethics of care is on the compelling moral salience of attending to and meeting the needs of the particular others for whom we take responsibility' (p. 10). Thus, the caring relationship is 'ethically basic' (Noddings, 2003: 3). In contrast to the dominant rationalist approaches, feminist notions take emotions such as sympathy, empathy, sensitivity and responsiveness as moral elements that 'need to be cultivated not only to help in the implementation of the dictates of reason but also to better ascertain what morality recommends' (Held, 2006: 10). In other words, the ethics of care typically appreciates the 'emotions and relational capabilities that enable morally concerned persons in actual interpersonal contexts to understand what would be best' (Held, 2006: 10).

Feminist ethics of care, differs from traditionally masculine approaches to morality, is sceptical of abstraction and reliance on reason and rationalist universal rules (Held, 2006: 10-11). It moves care away from 'universal moral principles' (Lawrence and Maitlis 2012) and links care to particular others rather than a generalised other (French and Weis, 2000; Liedtka, 1996). Furthermore, Tronto (1993) pushed the ethic of care into political discourse, arguing that we must understand care as a social practice rather than a disposition that is 'easy to sentimentalise and privatise' (Tronto, 1993: 118). In contrast to dispositions, practices are social phenomena, owned and controlled by groups that define their correctness and provide ways for members to learn them (Barnes, 2001). An ethic of care thus allows the struggles of organisational members to be situated and contextualised within their sociocultural underpinnings (Held, 2006; Tronto, 1993). Hence, feminist writing presents an ethic of care as an approach to morality emphasising the concrete needs of people with whom we are in a relationship.

Moreover, an ethic of care values 'growth' (Gilligan, 1982; Ruddick, 1980). That is, 'moving [the cared-for] towards the use and development of their full capacities, within the context of their self-defined needs and aspirations' (Liedtka, 1996: 185). This suggests that an important domain of discursive practice is how people construct their futures. Noddings (2003) describe this idea in terms of the hopes and dreams a mother might have for her child that 'set aside temptation to analyse and plan' (p. 30). Ruddick (1980) echoes this, arguing that an ethic of care implies an attitude towards the future of those we care for in which 'innovation takes precedence over permanence, disclosure and responsiveness over clarity and certainty’ (p. 352). Thus, a caring approach towards another person's future requires understanding, accepting uncertainty and working to foster growth; however, that person might understand it and however it might evolve.

A leader could not be expected to have such a close relationship with all of their employees. Therefore, we consider practices which help to foster caring relationships among members of staff (line managers/employees etc.) rather than constraining them into particular discourses. Liedtka (1996: 193) noted that 'the architecture of the organisation would need to be highly decentralised to give each individual the "reach" necessary to carry out the caring work on a daily basis, in an autonomous way'. In this study, we, therefore, consider how much 'reach' organisational members are given by the leader to construct their and others' futures in ways that are not predetermined. 


\section{Research design}

Some of the extant research largely depends on subordinates' perceptions and reactions for evaluating leaders' ethical practices (e.g. Den Hartog and Belschak, 2007; 2012). However, where power and the symbolic status of leadership are being abused, followers may express acceptance/ compliance even when leadership practices appear immoral/unethical (Sankowsky, 1995; Price, 2018). Thus, we move away from the sole dependence on followers' responses and perceptions (Price, 2018).

The empirical material used in this study is based on a study of sporty behaviours of a group of 24 sporty corporate executives in Sweden (e.g. Johansson, 2017). All the participants shared a similar belief that they, through a self-project in role modelling their lifestyle behaviours, may change the lives of their employees, enhancing work performances. For this work, we focus on the narrative and actions of one CEO (Adam), observing how he attempts to care by modelling lifestyle behaviours. To supplement this, we include observational material and extracts of informal conversations between the researcher and the employees (Swain and Spire, 2020).

\section{The empirical setting and methods}

This study concerns private lifestyle behaviours, including feelings, emotions and bodily senses. It is thus vital to protect the identities of all those discussed, and pseudonyms are used throughout. The name of the organisation is concealed, and characteristics which may identify it are masked as far as possible. Small details (i.e. locations/timescales/specific details of events) are amended upon the necessity to protect Adam's identity and that of his company.

Adam was the owner and the CEO of an engineering consultancy when the study was conducted between 2010 and 2014. We use Adam's story here for two reasons. First, Adam's story is representative of the broader approaches of the executives who participated. That is, lifestyle behaviours have become a new site where CEOs and executives build their identities as competent, influential and innovative 'athletic leaders' (e.g. Johansson, 2017). Second, while other participants proclaim their beliefs in influencing others through their own lifestyles (Johansson, 2017), Adam goes further, openly linking his personal sporting activities with the growth of his company. He uses this to justify his way of 'caring for others' through influencing their lifestyles. We see this as evidence that Adam is both an exemplar case and also a 'pioneer'. We look at the attempts of a male athletic CEO to enact ethical leadership through the lens of an ethic of care, drawing from detailed observations/interviews. We analyse his approach through a consideration of the norms and expectations often associated with female leadership (Pullen and Vachanni, 2020). Here, we scrutinise how Adam, as he often claims, incorporates athletic values such as striving for success, competitiveness and power (e.g. Petrie and Greenleaf, 2011) to lead others.

Adam's company has grown aggressively both organically and through acquisition. When the study was conducted, there were around 850 employees and most business activities took place in Sweden and Finland. The ratio between male and female employees is approximately $4: 1$. By the time the research was finalised, the company had diversified geographically and today has operations in Finland, Norway and Russia and has over 1600 employees. Today, the company has become market listed with over 2000 employees. The annual reports show that the ratio between male and female employees remains roughly at the same level.

Between 2010 and 2014, the first author met Adam eight times for interviews and in-depth observations. The semi-structured interviews contained general information on Adam's exercise routines, his belief in collective health management and influencing employees as a leader. People 
use language to make sense of their social reality, conveying values and beliefs that are vital to their sense of self (Weick, 1995). Hence, we take verbal narratives around Adam's experience (gleaned during both interviews and observations) as 'the reflexive construction and reproduction' of his values and beliefs (Alvesson, 2010: 212).

Adam, the eldest of three siblings, was in his forties when the study was conducted. Throughout the data collection, Adam enthusiastically used athletic metaphors and values to describe his leadership approach and self-management. Adam exercises for at least 2 hours every day. He engages in many sports and trains with former elite athletes and professional instructors. Adam believes that his athletic lifestyle is the reason he has succeeded in many aspects of life. His persistence in physical training requires prioritisation and disciplinary skills, and he feels this has given him the psychological strength to cope with high levels of stress at work and turbulence in his private life.

We include the comments and observational data from Adam's daily activities and from Adam's employees at several company events. One such event was a new employee education course introducing practices and organisational culture. Adam normally gives an opening speech on the notion of 'healthy' as a key vision for the company. The majority of the participants in this event were men in/around their forties. During coffee breaks, they, together with their CEO, enthusiastically discussed different company subsidised sporting events, and their plans to participate in them.

Crucial field notes were also gathered on the company's 50-year jubilee celebration. The event was centred around sports, athleticism, competition and health promotion. On the last day, a 'Mountain Challenge' was held involving around 1000 (of 1200) employees. During this event, the first author spoke with individuals who chose not to participate.

The first author paid attention to reactions from the employees and comments made in conversation, adding 'context' and 'authenticity', and unlocking otherwise missed opportunities to expand and enrich data (Swain and Spire, 2020). To comply with ethical guidelines, the first author was transparent about her role and the aim of her presence (Swain and Spire, 2020). The employees were informed that the content of the conversations might be used in anonymised form in research publications. The conversations were often centred around the topic of sporty lifestyles, such as employees' perceptions of the company's vision watchword 'healthy', and their own opinions or practices regarding being athletic. The length of informal conversations varied from 5 to $30 \mathrm{~min}$ depending on the circumstances, and they were documented in field notes.

\section{An interpretive approach}

As interpretive researchers, we are responsible for documenting and understanding the experiences reported by informants and for engaging in theorisation to reveal underlying meanings (unintended) and realities (Geertz, 1974; Schütz, 1962). In analysis, we identify how Adam uses his sporting endeavours to organise work processes based on his interpretations. This is, according to Schütz (1962), the 'first-order construct' of the social reality of the actors. Thereafter, we engage with the feminist literatures on the ethic of care (e.g. Held, 2006; Liedtka, 1996; Fisher and Tronto, 1990), to examine and interpret how Adam's good-willed intentions based on practices of self-care may influence his relations with others in unexpected or even unethical ways. For example Adam firmly believes that he benefits greatly from his sporty lifestyle. He therefore perceives influencing others as ethical. However, by taking the lens of feminist care ethics, we suggest that he fails to engage with the relational aspects of care or to promote them in his organisation. By scrutinising Adam's reality within feminist theories of the ethics of care, we connect the 'common-sense world' with the scientific world of theories (e.g. Schütz, 1962; Aspers, 2009). 


\section{Analysis}

Our analysis tackles Adam's expressions of care on personal, interrelational and organisational levels. On a personal level, we outline how Adam enacts the logic of self-care to pursue his objectives of becoming a competitive leader. On the relational level, we explore expressions of "caring for others' by drawing on feminist notions of relationality and an ethic of care. On the organisational level, we uncover how prevailing masculine values such as managerialist instrumentality, economic rationality and the promotion of power and success are concealed beneath Adam's healthy organisation. We consider how his approach limits the enaction of a feminist ethic of care among employees within his organisation.

\section{Becoming an 'authentic', athletic leader}

In this section, we focus on illustrating how Adam, by talking about his lifestyle and sporting activities, as well as his intention of caring for his health and that of others, manifests new elements in leadership that are, according to him, transformational, authentic and trustworthy. Adam links his vigorous athletic endeavours closely with the type of leader he aims to become. He is confident that he can impress and influence employees by 'walking the talk'. Taking this as a moral foundation, Adam underpins athletic values in his leadership approaches (e.g. Johansson, 2017). In modelling athletic behaviour, Adam hopes to transform himself from a 'good leader' to an extraordinary 'modern leader', influencing his employees in all aspects of their lives. By doing so, Adam highlights the linkage between sport and an idealised image of a leader:

I believe there is an unlimited source of energy within each individual. What we need to do is to energise this capacity and explore the hidden source of energy. But the key is to do the right things.

You can always become better. Since I am not a professional athlete, I often challenge my records in different sports. I think you need to do this to improve. I think the same rationale works in an organisation, too. Everyone needs to become better in different ways at work.

Here, Adam links sporting activities to improvements at work. Adam enacts sporty technologies of self-care primarily to live up to a societal bodily ideal rather than to challenge it, to create an idealised image of an 'athletic leader'. However, we find little critical self-reflection in his actions.

Everybody goes through difficult times in life and at work, to be active in life and exercise frequently has been my method in dealing with all kinds of obstacles. I feel good, energetic, full of inspirations when I live a healthy life. I believe this is the most significant part of my leadership approach.

For Adam, 'self-creation' involves being active, sporty and athletic. Adam believes that fitness of the body is the outcome of physical exercise, and such physical effort speaks about the quality of a person, especially a leader. He obviously uses the embodied aspect of the athletic image to reinforce the masculine-type leadership characterised by competitiveness, power, success-striving and aggression (e.g. Collinson and Hearn, 1994).

Leaders need to be on top of things. Once you lose control of yourself, your body becomes less fit. Similarly, being in control of a professional situation begins with keeping your body under control. High levels of competition come from this strength of self-control, too. People who cannot control their body can barely be trusted for controlling work situations. 
The above quote shows that Adam highlights self-disciplinary practices in his narratives, regarding health, and athletic endeavour as the necessary qualities of a leader and of a competent employee. Adam reproduces prevailing masculine values in his organisation and the moralising of the body (Cederstrom and Spicer, 2015; Dale and Burrell, 2000, 2014). By drawing from athleticism, he strengthens a masculine embodiment of leadership which negates bodies 'out of control'. Female, maternal, disabled and overweight bodies and bodies with less freedom to engage in such pursuits, those with caring responsibilities become self-evidently out of place, undesirable and inappropriate. Thus, his approach is attuned not to the needs of specific bodies but rather to an idealised body.

Furthermore, Adam not only role models athleticist values by maintaining a 'healthy' body image, but also he expresses distrust of those who do not or cannot conform. He discusses the advantages of introducing health criteria into selection/promotion processes. Conrad and Walsh (1992) argued that health interventions implemented at workplaces have contributed to the formation of a new health ethics serving instrumental managerial purposes. Johansson et al. (2017) also finds that company CEOs and executives create managerial athleticism through working out and relating such endeavours to leadership performances. In this study, Adam uses physical mastery to practice reflexivity in leadership (e.g. Crocket, 2017), but this does not extend to considering how the needs of his employees may differ from his own, or how success may be viewed differently among them.

For Foucault $(1984,1986)$, ethical substance identifies the self as the focus of ethical conduct; this can be one's body or thoughts (e.g. Crocket, 2017). Adam inscribes his activities in sports with moral markers of 'self-control' and 'self-discipline', hoping that, with his 'moralised' body, he appears 'authentic' and 'trustworthy' and differs from conventional leaders, evaluated on work performance (Bass, 1985).

There is, however, a lack of ethical, critical self-awareness (Markula, 2003: 101) in Adam's athletic leadership. He advocates embodied attributes upholding the authority and legitimacy of his position but expresses little self-reflexivity targeted at contesting traditional managerial notions and leadership values. The leadership values that Adam demonstrates all fall back into the same prevailing masculine characteristics: desire for success, competitiveness, power and self-reliance (Kerfoot and Knights, 1998). Thus, Adam fails to engage in a relationship with his employees, or encourage in his organisation an environment that would consider and address employees' needs.

\section{Ethical care for others or an instrumentalist approach?}

In this section, we focus on how Adam relates to others through attempting to express 'care'. Adam uses the word 'care' frequently both in interviews and speech when discussing his employees. Our data show that Adam believes that 'modern leadership is a broad and more inclusive concept in modern times', and that 'this means, we should be able to make changes in people's lives in many ways'. We, therefore, question how far his care for others is rooted in instrumentalism, and we cast doubt over how his desire to influence others in 'all aspects of their lives' can be construed as caring.

First, we find that Adam's leadership approach embeds instrumentality into his care for others. Although Adam seeks to address employee feelings/emotions, this seems to be less based on being a part of and encouraging empathy and responsiveness among his employees, and more on Adam's desire to pass on his lifestyle. Tellingly he seeks to employ and encourage those that mirror him. For example Adam claims that emotions are effective ways to influence employees and gain loyalty. Alongside affective speech, Adam also enacts embodied emotional expressions to affect his relations with employees. He believes that a sincere hug brings him closer to his employees. 
I mean, I really care about all of them. I need to let them know about it. So I am never hesitant in showing this. I will always give them a hug. I definitely come closer to them when I show my emotions and care towards them through hugging them. I hope they are able to understand that I wish they could live life in the same way as I do, because I benefit so much from my lifestyle.

During the company's 50 years jubilee, Adam organised a 2-day event at a Ski resort. Adam hugged all the employees at the beginning of the 2-day conference.

This is my way of expressing myself to my employees. I believe they can feel the energy, the passion, inspiration that I intend to transfer to them through this hug. The best way of motivating and inspiring someone to be willing to make efforts to do sports, to workout, to work hard is to make them feel that you care about them. I think this hug says a lot.

Adam believes that his hugs are a way he expresses himself to others and encourages them to live in the way he does. He is clear and bold about his desire to inspire his employees to commit to a healthy, sporty lifestyle.

Although Adam seems well-intentioned, his approach is one directional. Employees' 'selfdefined needs and aspirations' (Liedtka, 1996: 185) are absent from his initiatives. Instead, employees are subject to normative directives on what it means to be healthy. In promoting universal approaches to health and fitness with ferocity, a more nuanced perspective that might attend to individual needs is not facilitated among staff. Those who engage with the 'health' narrative are viewed positively and those who do not are thought to be in need of an attitude adjustment. Emotion and affection, as well as Adam's hugs, are linked with efficiency/productivity (Islam, 2013; Price, 2018; Rhodes and Pullen, 2018).

Moreover, Adam discussed bonding experiences with his colleagues through sharing one's weaknesses with others:

When I am injured, I share that with my colleagues and with those who sometimes exercise with me. This is like you bound with each other without words. You will understand each other's pain, difficulties and strength all at the same time. I share this with people, so that they know I can also be hurt and weak, but I always come back.

On several occasions, field notes reveal that Adam and his male colleagues shared a chat in the coffee room about their injuries from sporting activities. When talking about the pain of strained muscles, broken tendons or a tough training session, they seemed to speak about it with joy, pride and satisfaction not distress. These shared experiences created a sense of solidarity among the men, already similar in age and physique. In such circumstances, where the recipients were ready to respond, it seemed that Adam was able to pass on his 'care' and 'emotional influence'. In doing so, however, he privileges the male athletic body over those who are 'different' from himself. He spends time and energy with those who seem to be similar to him, recognising their sporting achievements and conquests as work-related and lending them, but not others, his approval. This selective approval risks causing inequality and unfairness. An ethic of care values emotions such as empathy and responsiveness (Held, 2006 in Linsley and Slack, 2013: 287) but does not sit well with the excessive formalism, the calculative ratiocination and the impersonal perspective of the dominant moral traditions (Liedtka, 1996: 181). Drawing on this, we find an absence of the relational ethics of care in the overt instrumentalist approach Adams takes. 
Furthermore, Adam continuously links employee lifestyle behaviours with his leadership practices. He designates himself the authority to prescribe solutions to solve others' problems through modelling his own behaviours. This, risks two outcomes antithetical to a feminist ethic of care. The first is the loss of particularity resulting in the dehumanisation of individuals in need (e.g. In Liedtka, 1996: 183). The second is that 'caregiving' becomes an imposition of values upon caretakers (Nicholson and Kurucz, 2019).

Moreover, the types of 'problems' Adam identified, such as perceived unhealthiness or bodies 'out of control', were not seen as an issue by everyone. Adams' expressions of care and his emotional appeals did not convince all of his employees. During the Mountain Challenge event at the company's 50th Anniversary (attended by around 1000 employees), some employees chose to stay in the hotel enjoying a relaxing drink, smoking and chatting with colleagues despite the high level of encouragement they had received from their CEO. They openly expressed their thoughts regarding the sporty lifestyle and 'athletic leader'.

I have never been a sporty person in my whole life. I like to have a smoke or two. I know in this company they don't like it. But it is my choice, and I am not going to change it for anyone.

You see there are many of us that prefer to sit here and enjoy our beer, potato chips and chit-chat instead of doing the Mountain Challenge with the others. It is fine that our boss is doing what he likes to do, but I don't think this will affect my life in any way. I think it is a bit too much that he tries to change all of us.

The above quotes speak for the discrepancy between Adam's expressions of care and the views of some of those he attempts to care for. Instead of feeling cared-for, these employees perceive Adam's influence as an intrusion into their way of life and freedom to choose. Adam is determined about what is right and wrong. His judgements are based on his moralising of the body, the distinction between 'fit' and 'unfit', 'normal' and 'abnormal' and health and lifestyle behaviours. Although Adam repeatedly claims an awareness of the personal struggles of others, his response is to prescribe his own ways to deal with them.

In taking a universal approach to solutions for the perceived 'problems' of his employees, Adam constructs employee issues as fundamentally private, although he is very interested in helping employees he believes need to become more empowered. Conversely, a feminist ethic of care would draw attention to the political and public processes at play (Lawrence and Maitlis, 2012). The sociocultural conditions that may cause an individual to appear unfit or unhealthy, or which may make them seemingly less desirable as employees, can relate to a broad range of issues including but by no means limited to: gender, poverty, class, caring responsibilities, disability, maternity, the maternal body, etc. If care is 'an attention to one's own presence in the world' (Ciulla, 2009:3), then Adam does not effectively care because he is unable to see how his own practices and beliefs may have unintended consequences on others whose circumstances or desires may be very different from his own.

Nicholson and Kurucz (2019) argues that there is a significant distinction between caring and problem-solving. This means people ought to avoid solely focussing on finding solutions to problems but should instead be attentive to the emotional states and needs of others. Thus, ethical caring only applies to those persons that we care for. The practices associated with an ethics of care should be largely connected to the needs of others and far less to the intention to provide care (Noddings, 2003). As a self-regarded caregiver, however, Adam primarily imposes his solutions on people without encouraging a dialogue (e.g. West, 1993). 


\section{A homogeneous, masculine, healthy organisation?}

In this section, we analyse how Adam interweaves his beliefs in a (physically) active lifestyle with his desire to establish an organisational culture where 'healthy' behavioural norms, highly competitive physical bodies and self-control/self-discipline are emphasised. Adam conforms to and promotes a discourse of health and well-being, continual improvement and limitless potential. His care revolves around the fit body at work, with the promotion of a productive body and therefore a productive company. Based on an economic rationality, Adam links his 'care' of employees' well-being with a vigorous effort to promote masculine values of competitiveness and striving for power/success (e.g. Collinson and Hearn, 1994). We, therefore, question the ethics of care in such practices.

Adam is determined to craft a 'healthy' organisation. However, his approach to care is built upon the rationale that striving for good health leads to infinite self-projects so that people constantly seek new challenges, set new goals and strive for successes.

For instance, Adam links his 'caring for others' closely with organisational outcomes such as performance, productivity and efficiency. Adam has a 'balance sheet' to explain this. 'To keep employees healthy is a cost-effective action. For every single krona I invest in my employees' good health, there will be four times the return of investment'. The return on investment, according to Adam, is enhanced productivity, efficiency and reduced absences. In this way, as Islam suggests, employees become seen as 'bundles of human capital rather than as conscious freely choosing agents' (Islam, 2013:237). Caring through providing an uninhibited space in which the needs of others can be engaged with is inhibited.

The essence of becoming healthy, for Adam, is that there is no direct satisfaction in reaching a state of health, but rather in the endless pursuit of good health. As shown in the quote below, Adam believes that leading people into a process where they voluntarily engage with continual improvement, and discipline provides a competitive advantage.

What we do to keep in good health is to improve ourselves constantly, to challenge both physical and mental limits so that we become even better. A leader who can influence employees to keep 'healthy' can also make them always improve themselves. A healthy organisation is therefore the one that everybody is willing to improve in all circumstances.

Adam's 'care' is thus conditional. His approach sets up new organisational norms based on health, lifestyle and physicality. Adam deliberately expresses respect for those with athletic values, describing them as mentors and 'life coaches'. He openly praises those who engage in sport frequently and articulates disappointment and concern for employees who think differently.

I care about my employees. I hope those who are not living a healthy life can change their lifestyle. They need to change how they live their lives. It is not good for them to keep on living like this: Smoking, drinking or refusing to do any exercise, sitting in front of TV or computer when not working ... I believe I can help those employees who are not knowledgeable about healthy living. I can be a role model for them. I have 'healthy' as one of the value watchwords of the company. I am determined to change them.

Adam moralises the body. He associates lifestyle and health with organisational benefits. Furthermore, by emphasising self-control and discipline as the managerial philosophy, Adam implicitly dismisses those who will not or cannot conform. 
There is a TV programme called 'You are what you eat'. I think you are 'what you do' and 'how you look'. If you look healthy and fit, people naturally believe you can control yourself, discipline yourself and manage your own life. They will trust such a person to manage the company, too.

Adam believes that physical activities are indications of whether people are in control of their lives. He admits that he gives 'polite' reminders to those employees who 'seem to be drinking a bit too much' or 'not keeping very healthy habits'. With this, Adam encourages a blame culture and constructs lifestyle struggles as 'problems of choice' without noting any broader contextual issues. Adam's practices are problematic because he overlooks the social and cultural conditions crucial for making his lifestyle personally desirable and achievable (Liedtka, 1996). Adam implements health screening programmes and introduces new forms of organisational categorisation that enrol employees in exhaustive self-projects (Watson, 2008). With his 'caring intentions', he connects good health with norms of competence and professionality at work: yet his 'good intentions' run the risk of being perceived by employees as transgressing leadership boundaries and leading to demotivation among employees (e.g. Thanem, 2013).

\section{Discussion and conclusions}

A feminist ethic of care involves challenge and support; it can be a matter of 'tough love', but it is personal, it focuses on 'self-defined needs' and is concerned with persons not profits (Liedtka, 1996: 185). Care 'is situated within the context of a community, derives its shared focus from the needs of that community and is only sustainable with the support of that community' (Liedtka, 1996:187). Drawing from these notions, we show how Adam's 'care for others' is expressed through leadership rhetoric that intensifies an asymmetrical power relationship between caregiver (the CEO) and caredfor (e.g. the employees) (e.g. West, 1993). The community our sporty CEO creates, is one in which a universal view of health and athleticism is promoted. It is the needs of the organisation and the CEO's assumptions about individual needs that become prioritised. The CEO claims the right to operationalise a system of managerial principles in the organisation to impose values of athleticism into the private lives of employees. We therefore contend that such 'care' is decoupled from the fundamental notion of caring as always involving "“feeling with" - receiving the other, rather than projecting one's own view onto the other' (Liedtka, 1996:185).

In this study, we offer a critique of the leadership trend that involves leaders' lifestyle behaviours being used as moral and ethical indicators for others to follow (Thanem, 2013; Johansson, 2017). We only expunge one in-depth case here and so cannot make broad generalisations, but we note that our findings chime with others who have commented on the problematic nature of using the leader as a panacea for morality and ethics (Thanem, 2013). We have questioned how far an ethics of care can flourish in leadership practices that may appear to be 'ethical', 'authentic', or 'transformational' on the surface but conform only to instrumental rather than substantive rationalities, privileging masculine over feminine. A feminist ethic of care has often been used to assess the ethics of female leaders (Pullen and Vachanni, 2020), but here we use it to consider the ethical approach of a male leader. We bring substantive rationalities, through an ethic of care, to bear on the ethics of a patriarchal leadership style.

Methodologically, we move away from the sole dependence on followers' responses and perceptions as evidence for ethicality in leadership (Price, 2018). Drawing from feminist works on an ethics of care, we explore ethical dilemmas inherent in transforming practices of self-care into ethical practices for caring for others. We delve into the instrumental forms of rationality that are embedded in current leadership approaches. In this case, we highlight how the power and 
domination expressed through the male athletic body in the name of 'caring for others' hinders the development of a relational approach that would see the specific needs of employees considered.

Furthermore, appraising this type of athletic leadership through a feminist ethic of care also provides unique insights into the ethicality of the leader as a moral project. We recognise Adam's morality from the ethical practices of self-care he enacts. He treats himself as an aesthetic and moral project (Foucault, 1986; Crocket, 2017; Gerdin et al., 2018). Nevertheless, the sporty CEO's practices relating to 'aesthetical self-stylisation' and 'critical self-awareness' in sports (e.g. Llyod, 1996: 98) are of little ethicality through a feminist lens because they fail to challenge dominant discourses regarding masculine tendencies in leadership (Markula, 2003; Markula and Pringle, 2006). Instead, these tendencies are embodied and strengthened in Adam. Our findings serve as a critique to normative theorising of ethical leadership taking 'honest' and 'trustworthy' 'role modelling' as the self-evident moral foundation of ethical leadership practices (e.g. Brown et al., 2005).

Ultimately, we find that when a leader fails to consider the needs and opinions of employees but rather only focuses on productive human resources (Islam, 2013) and role modelling, they do not successfully conduct ethical leadership. Although well-intentioned, the sporty CEO's self-creation practices in sports, ultimately re-entrench inequality and traditional modes of subjectivation that relate to the careful management of the body; whereas other types of bodies, overweight, 'unfit', maternal, disabled etc. do not fit in with the picture of 'health' presented (Gatrell, 2015).

Western organisational leaders often concern themselves with establishing moral or ethical leadership by incorporating embodied self-creation via specific lifestyle behaviours. They may attempt to embody 'honesty', 'trustworthiness' or 'authenticity' as described in the theory of ethical leadership (Brown and Treviño, 2006; Brown et al., 2005: 120). When self-care through embodied self-creation becomes concerned with strongly influencing employees (Yukl, 2002), relationality disappears and an ethic of care with it. This self-creation then, particularly when directed towards employees, needs to be scrutinised. While we recognise the impossibility of asking any leader to adopt a personalised approach to every employee, what we do note in this case is the restrictive nature of the form of self-care that some leaders promote. When organisational leaders see their way as the one way of being normal, healthy and fit, they squeeze out other possibilities and other voices from discussion or appreciation in the organisation. There is limited space left in which alternative discourses can flourish. Care for others becomes the introduction and enforcement of new bodily or behavioural norms. The traffic light system is perhaps the most striking example of this. Those viewed as unathletic either through personal preferences or because of disability, pregnancy and caring responsibilities find that their bodies are excluded (Catrell et al., 2017; Sinclair, 1998, 2005).

The transformation of an ethics of self-care into care for others involves a profound understanding of care as an interdependent phenomenon where the cared-for's voice is equally valuable. 'Every ethical or unethical thing that a leader does can have a ripple effect' (Ciulla, 2005: 329). The unique position leaders have determines their fate in frequently facing ethical challenges in their actions (Ciulla, 2005). Leaders must recognise the subtle distinction between caring for others/encouraging this among staff and promoting/orchestrating the management of employees' entire 'lifeworld' (e.g. Thanem, 2013; Johansson et al., 2017).

The normative construction of ethical leadership emphasises selfhood as a sticking point of ethical leadership (Brown et al., 2005), raising issues for leaders and followers. Our study reveals the ethical difficulties that result from the self-proclaimed ethical practices of one leader who is willing to enact self-creation as an opportunity to inspire and generate change among others in- and outside the workplace. The prominence of the well-being agenda in organisations across the west (Cederstrom and Spicer, 2015) suggests that there are many others who are motivated in enrolling 
themselves and others in an infinite process of becoming. We, therefore, suggest that future studies within ethical leadership could scrutinise leaderships influence beyond the workplace and into the everyday lives of employees.

\section{Declaration conflicts of interests}

The author(s) declared no potential conflicts of interest with respect to the research, authorship and/or publication of this article.

\section{Funding}

The author(s) received no financial support for the research, authorship and/or publication of this article.

\section{ORCID iD}

Janet Johansson (1) https://orcid.org/0000-0003-2125-5451

\section{References}

Alvesson M (2010) Self-doubters, strugglers, storytellers, surfers and others: images of self-identities in organization studies. Human Relations 63(2): 193-217.

Aspers P (2009) Empirical phenomenology: a qualitative research approach. The Indo-Pacific Journal of Phenomenology 9(2): 1-12.

Avolio BJ and Gardner WL (2005) Authentic leadership development: getting to the root of positive forms of leadership. Leadership Quarterly 16(3): 315-338.

Avolio BJ, Gardner W, Walumbwa FO, et al. (2004) Unlocking the mask: a look at the process by which authentic leaders impact follower attitudes and behaviours. Leadership Quarterly 15(6): 801-823.

Barnes B (2001) Practice as collective action In: Schartzki TR, Knorr Cetina K and von Savigney E (eds). The Practice Turn in Contemporary Theory. London: Routledge, 17-28.

Bass B (1985) Leadership and Performance beyond Expectations. New York: Free Press.

Bass BM and Avolio BJ (1993) Transformational leadership and organisational culture. Public Administration Quarterly 17(1): 112-121.

Bass BM and Steidlmeier P (1999) Ethics, character, and authentic transformational leadership behavior. The Leadership Quarterly 10(2): 181-217.

Brien A (1998) Professional ethics and the culture of trust. Journal of Business Ethics 17: 391-409.

Britton DM (2000) The epistemology of the gendered organisation. Gender \& Society 14(3): 418-434.

Britton DM and Logan L (2008) Gendered organisations: progress and prospects. Sociology Compass 2: $107-121$.

Brown ME and Treviño LK (2006) Ethical leadership: a review and future directions. The Leadership Quarterly 17: 595-616.

Brown ME, Treviño LK and Harrison, D (2005) Ethical leadership: a social learning perspective for construct development and test. Organisational Behavior and Human Decision Processes 97: 117-134.

Cederstrom C and Spicer A (2015) The Wellness Syndrome. Cambridge UK: Polity Press.

Chartered Institute of Personnel and Development CIPD (2019) Health and Wellbeing at work survey. Available at: https://www.cipd.co.uk/Images/health-and-well-being-at-work-2019.v1_tcm18-55881.pdf.

Ciulla JB (2004) Ethics, the Heart of Leadership. 2nd ed. Westport: CT: Praeger.

Ciulla JB (2005) The state of leadership ethics: and the work that lies before us. Business Ethics: A European Review 14(4): 323-335.

Ciulla JB (2009) Leadership and the ethics of care. Journal of Business Ethics 88(1): 3-4.

Collinson D and Hearn J (1994) Naming men as men: implications for work, organisation and management. Gender, Work and Organization 1(1): 2-22. 
Conrad P (1994) Wellness as virtue: morality and the pursuit of health. Culture, Medicine and Psychiatry 18(3): 385-401.

Conrad P and Walsh DC (1992) The new corporate health ethic: lifestyle and the social control of work. International Journal of Health Services 22(1): 89-111.

Crocket H (2017) Problematizing foucauldian ethics: a review of technologies of the self in sociology of sport since (2003). Journal of Sport and Social Issues 41(1): 21-41.

Dale K and Burrell G (2000) What shape are we in? Organisation theory and the organised body. In: Hassard J, Holliday R and Willmott H (Eds.), Body and Organization. London: SAGE, pp. 15-30.

Dale K and Burrell B (2014) Being occupied: an embodied re-reading of organisational 'wellness'. Organisation 21(2): 159-177.

Den Hartog DN and Belschak FD (2007) Personal initiative, commitment and affect at work. Journal of Occupational and Organizational Psychology 80(4): 601-622.

Den Hartog DN and Belschak FD (2012) Work engagement and machiavellianism in the ethical leadership process. Business Ethics, Issue 107: 35-47.

Dirks KT and Ferrin DL (2002) Trust in leadership: meta-analytic findings and implications for research and practice. Journal of Applied Psychology 87: 611-628.

Fisher B and Tronto J (1990) Toward a feminist theory of caring. In Abel E, \& Nelson M (eds) Circles of Care. Albany: SUNY Press.

Foster D (2018) The health and well-being at work agenda: Good news for (disabled) workers or just a capital idea? Work, Employment and Society 32(1): 186-197.

Foucault M (1984) ‘On the geneaology of ethics: an overview of work in progress?' In: Rabinow P (ed). The Foucault Reader. New York: Pantheon.

Foucault M (1986) The Care of the Self. New York: Pantheon.

Foucault, M (1994) The ethic of care for the self as a practice of freedom. An interview with michel foucault on anuary 20, 1984, conducted by R. Fornet Betancourt, H. Backer and A. Gomez-Muller. In: The Final Foucault. Cambridge, MA: MIT Press, pp. 1-20.

French W and Weis A (2000) An ethics of care or an ethics of justice. Journal of Business Ethics 27: 125-136. Gardner WL and Avolio BJ (1998) The charismatic relationship: a dramaturgical perspective. Academy of Management Review 23(1): 32-58.

Gatrell P (2015) The Making of the Modern Refugee. Oxford: Oxford University Press.

Gatrell C, Cooper C and Kossek EE (2017) Maternal bodies as taboo at work: new perspectives on the marginalising of senior level women in organisations. Academy of Management Perspectives 31(3): 239-252.

Geertz C (1974) "From the native's point of view": on the nature of anthropological understanding. Bulletin of the American Academy of Arts and Sciences 28(1): 26-45.

Gerdin G, Pringle R \& Crocket H (2018) Coaching and ethical self-creation: problematising the "efficient tennis machine". Sports Coaching Review 8(1): 1-19.

Gilligan C (1982) In A Different Voice. Cambridge, MA: Harvard University Press.

Harvey G (2019) Corporate wellness: what, why not and whither? Employee Relations: The International Journal 41(4): 638-648.

Heidegger M (1996) Being and Time. Albany: SUNY Press.

Held V (2006) The Ethics of Care: Personal, Political, and Global. New York: Oxford University Press.

Islam G (2013) Recognising employees: reification, dignity and promoting care in management. Cross Cultural Management. An International Journal 20(2): 235-250.

Johansson J (2017) "Sweat Is Weakness Leaving the Body": A Study on the Self-Presentational Practices of Sporty Top Managers in Sweden. Stockholm: Stockholm Business School, Stockholm University.

Johansson J, Tienari J and Valtonen A (2017) The body, identity and gender in managerial athleticism. Human Relations 70(9): 1-27. 
Kerfoot D and Knights D (1998) Managing masculinity in contemporary organizational life: a managerial roject. Organisation 5(1): 7-26.

Knights D and O'Leary M (2006) Leadership, ethics and responsibility to the other. Journal of Business Ethics 67: $125-137$.

Knowles JH (1977) The responsibility of the individual. Daedalus 106: 57-80.

Kouzes JM and Posner BZ (2014) Credibility: How Leaders Gain and Lose it, Why People Demand it. San Francisco, CA: Jossey-Bass.

Lawrence TB and Maitlis S (2012) Care and possibility: enacting an ethic of care through narrative practice. Academy of Management Review 37(4): 641-663.

Liedtka JM (1996) Feminist morality and competitive reality: A role for an ethic of care? Business Ethics Qyarterly 6(2): 0179-0200.

Linsley PM and Slack RE (2013) Crisis management and an ethic of care: the case of Northern rock bank. Journal of Business Ethics 113(2): 285-295.

Llyod M (1996) A feminist mapping of Foucauldian politics. In: Hekman S (ed). Feminist interpretations of Michel Foucault. University Park: Pennsylvania State University Press, 241-264.

Maravelias C (2015) 'Best in class'. Healthy employees, athletic executives and functionally disabled jobseekers. Scandinavian Journal of Management 31: 279-287.

Markula P (2003) The technologies of the self: sport, feminism, and Foucault. Sociology of Sport Journal 20: 87-107.

Markula P and Pringle R (2006) Foucault, Sport and Exercise: Power, Knowledge and Transforming the Self. New York: Routledge.

Nicholson J, and Kurucz E (2019) Relational leadership for sustainability: building an ethical framework from the moral theory of 'ethics of care'. Journal of Business Ethics 156(1): 25-43.

Noddings N (2003) Caring: A Feminine Approach to Ethics and Moral Education, Berkeley: University of California Press.

Petrie TA and Greenleaf C (2011) Body image and athleticism. In: Cash TF, et al. (ed), Body Image: A Handbook of Science, Practice, and Prevention (ss. 206-220). New York: The Guilford Press.

Price T (2018) A "critical leadership ethics" approach to the ethical leadership construct. Leadership 14(6): 687-706.

Pullen A and Vachhani SJ (2020) Feminist ethics and women leaders: from difference to intercorporeality. Journal of Business Ethics 1-11.

Rhodes C \& Pullen A (2018) Critical business ethics: from corporate self-interest to the glorification of the sovereign pater. International Journal of Management Review 20(2): 483-499.

Ruddick S (1980) Maternal thinking. Feminist Studies 6: 342-367.

Sankowsky D (1995) The charismatic leader as narcissist: understanding the abuse of power. Organizational Dynamics 23(4): 57-71.

Schütz A (1962) Collected Papers I: The Problem of Social Reality. The Hugue: Martinus Nijhoff.

Sinclair A (1998) Doing leadership differently. Melbourne: Melbourne University Press.

Sinclair A (2005) Body possibilities in leadership. Leadership 1: 387-406.

Spicer A and Scott B (2015) Corporate wellness programs make us unwell. Harvard Business Review, 93(5), 28-29.

Stevenson D and Farmer P (2017) Thriving at work: the Stevenson/farmer review of mental health and employers. https://www.gov.uk/government/uploads/system/uploads/attachment_data/file/658145/thriving-atwork-stevenson-farmer-review.pdf

Swain J and Spire Z (2020) Forum: Qualitative Social Research 21(1): 163-184.

Thanem T (2013) More passion than the job requires? Monstrously transgressive leadership in the promotion of health at work. Leadership 9: 396-415.

Tronto J (1993) Moral Boundaries: A Political Argument for an Ethic of Care. New York, NY: Routledge. 
Watson TJ (2008) Managing identity: identity work, personal predicaments and structural circumstances. Organisation 15(1): 121-143.

Weick K (1995) Sense making in Organizations. Thousand Oaks, CA: Sage.

West C (1993) Race Matters. New York: Vintage Books.

Yukl G (2002) Leadership in Organizations. 7th edition. New Jersey: Prentice Hall Pearson.

\section{Author biographies}

Dr Janet Johansson. The first author of this study is Dr Janet Johansson. She gained her doctoral degree from Stockholm Business School, Stockholm University in Sweden. She now holds a senior lecturer position at Linköping University in Sweden. The focus of Dr Johansson's research is primarily on leadership. Particularly, she focuses on lifestyle behaviours and their impact on leadership practices and the identity work of leaders, as well as relations between leaders and employees. Taking a critical leadership studies approach, Dr Johansson problematises the instrumental pursuits embedded in the seemingly benevolent influencing processes of leaders. $\mathrm{Dr}$ Johansson is currently researching the issues of equality, diversity and inclusion in the performing arts industry in Sweden. With a theoretical focus on ethics, she looks at the role of leadership and management in obtaining equal, diverse and an inclusive organisational culture. She also scrutinizes organisational responsibility in the creation of unequal, unjust and exclusionary regimes at work.

Dr Michaela Edwards completed a PhD at Lancaster University in 2015. She now holds a senior lecturer post at Nottingham Business School in the United Kingdom. Dr Edwards is a critical management scholar. Her research interests focus on problematising the managerialisation of public sector services, seeking to think through the relationship between managerialisation and instrumental or substantive rationalities. Dr Edwards is interested in what care ethics at work can add to our understanding of leadership and management. She has additional related interests in the areas of well-being at work and organisational psychoanalysis. Dr Edwards is currently doing research on issues of line manager support for the well-being of employees and on the working environment for older academics. 